\title{
A System Review and Meta-Analysis of Canaloplasty Outcomes in Glaucoma Treatment in Comparison with Trabeculectomy
}

\author{
Bing Zhang, Jie Kang, and Xiaoming Chen \\ Department of Ophthalmology, West China Hospital, Sichuan University, 37 Guo Xue Xiang, Chengdu 610041, China \\ Correspondence should be addressed to Xiaoming Chen; chenxm58@163.com
}

Received 22 December 2016; Accepted 1 March 2017; Published 30 April 2017

Academic Editor: Gianluca Scuderi

Copyright (c) 2017 Bing Zhang et al. This is an open access article distributed under the Creative Commons Attribution License, which permits unrestricted use, distribution, and reproduction in any medium, provided the original work is properly cited.

\begin{abstract}
Purpose. This system review studied the efficiency and safety of canaloplasty (CP) and compared the outcomes between CP and trabeculectomy (TE). Methods. Literatures were searched in PubMed and EMBASE. The meta-analysis was conducted on the postoperative outcomes in $\mathrm{CP}$ and then on the differences of outcomes between CP and TE. Results. In the meta-analysis, IOP decreased by 9.94 (95\% CI 8.42 to 11.45) $\mathrm{mmHg}$ with an average AGM reduction of 2.11 (95\% CI 1.80 to 2.42) one year after $\mathrm{CP}$. The IOP reduction was significantly higher after TE than after CP, with an average difference of 3.61 (95\% CI 1.69 to 5.53 ) $\mathrm{mmHg}$ at 12 months postoperationally. For complications, the incidence of hyphema was significantly higher in $\mathrm{CP}$ and the Descemet membrane detachment was just reported in CP, with an incidence of $3 \%$. However, the incidence was significantly lower in CP of hypotony and of choroidal effusion/detachment. Meanwhile, suprachoroidal hemorrhage and bleb needling were only reported in TE. Conclusions. CP was less effective in IOP reduction than TE, but CP was able to achieve similar postoperative success rates and reduce the number of AGMs likewise. CP was also associated with lower incidence of complications. More high-quality researches are needed in the future to verify our findings in this system review.
\end{abstract}

\section{Introduction}

Intraocular pressure (IOP) is by now the most proven treatable factor in glaucoma, and lowering IOP has long been associated with slowing the damages by glaucoma $[1,2]$. Trabeculectomy (TE), since firstly being introduced in the 1960s, has remained the standard surgery of IOP control in glaucoma [3]. However, the relatively high incidence of complications of TE $[3,4]$ has encouraged the development of new surgery methods.

Canaloplasty $(\mathrm{CP})$ was a nonpenetrating surgery (NPS) performed with a microcatheter (iTrack; iScience Surgical Corp.). During CP, the Schlemm canal is expanded circumferentially injecting a small amount of high-weight molecular viscoelastic agent with iTrack and then a suture loop is placed to apply tension to the trabecular meshwork when iTrack is retracted [5]. CP has been performed as one major NPS in open-angle glaucoma treatment for years. However, no system review of $\mathrm{CP}$ to evaluate its efficiency and complications in the treatment of glaucoma has been published by now as far as we know. This study firstly made a system review of
$\mathrm{CP}$ and then compared the efficiency and complications between $\mathrm{CP}$ and TE.

\section{Methods}

This research was accorded to a predetermined protocol based on the Cochrane Handbook for Systematic Reviews of Interventions [6]. Review board approval was not required as no patients were enrolled.

2.1. Eligibility Criteria. Studies which met the following criteria were considered eligible: (1) participants diagnosed with glaucoma regardless of age, sex, or race, studies limited in patients with another failed antiglaucoma surgery were excluded; (2) interventions, included but not limited to CP, with or without phacoemulsification; (3) research types, both prospective and retrospective studies, excluding case reports and reviews; (4) outcomes: included but not limited to IOP, the follow-up was at least 6 months; (5) for literatures with overlapping data, only the one with the largest sample and then the longest follow-up was included. 


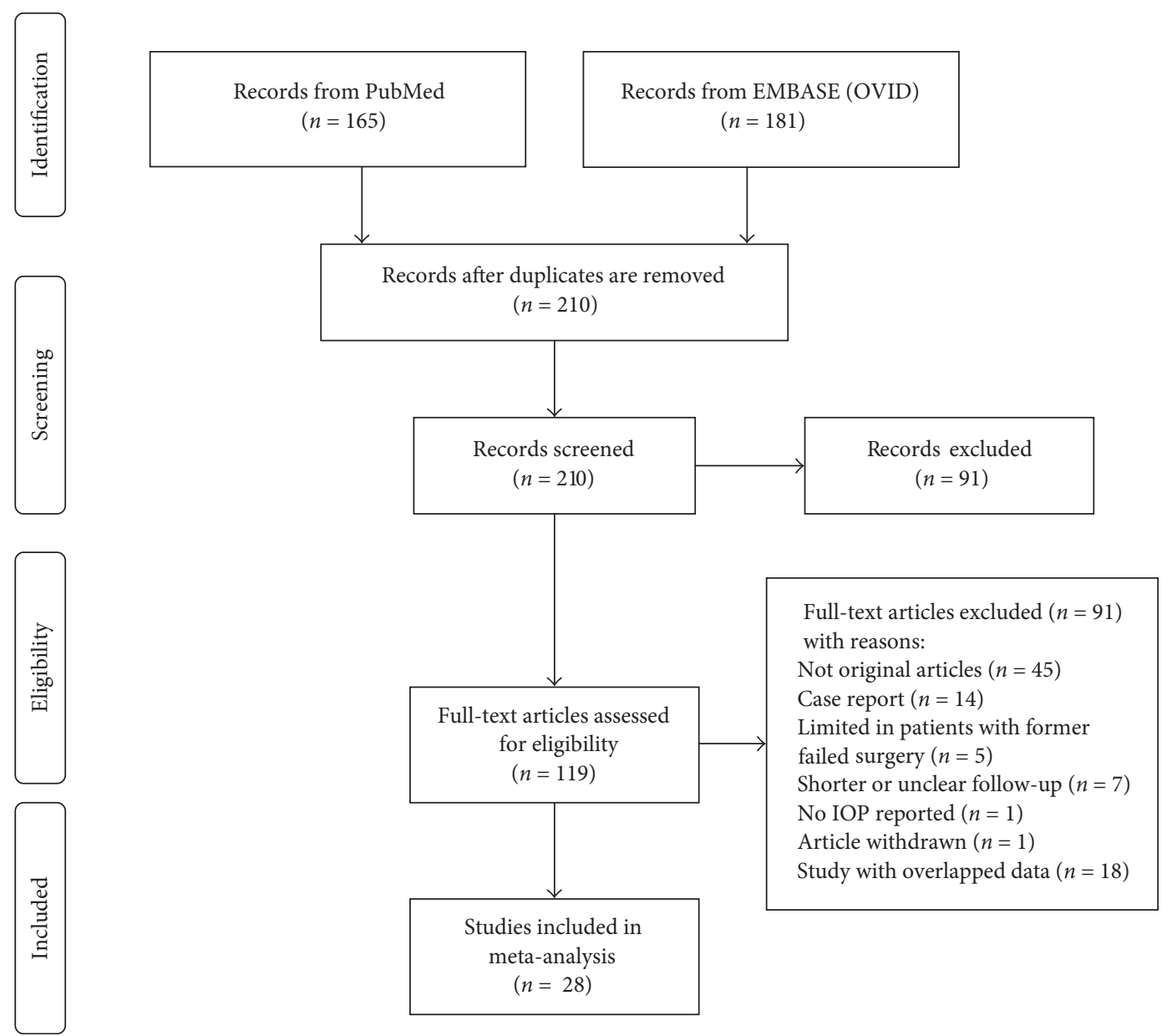

Figure 1: Flow diagram for study selection.

2.2. Search Strategies. PubMed and EMBASE were searched for literatures published up to April 1, 2016, in any language with the following strategies: ((circumferential OR 360) AND (viscocanalostomy OR viscodilat*)) OR canaloplasty. No unpublished studies were searched. After removing duplicate records, two reviewers (Bing and Jie) independently decided whether a study met the inclusion criteria; exclusion reasons were given to every literature not included.

2.3. Outcome Measures. The primary outcomes were the changes in IOP and the number of antiglaucoma medications (AGMs). The secondary outcomes were the complete and qualified successful rates and the incidence of adverse events. A complete success is defined as that a confirmed IOP is less than a given level without any AGMs; a qualified success is defined as that a confirmed IOP is less than a given level with or without AGMs [7]. The outcomes and research information were extracted by two researchers (Bing and Jie) independently.

2.4. Statistical Analysis. The meta-analysis was conducted with the software Review Manager V5.2 (Cochrane Collaboration). The changes in IOP and AGMs after CP were metaanalyzed in three subgroups, CP standalone, CP with phacoemulsification (PCP), and CP mixed (the former two subgroups mixed in the original papers). The mean between-group difference $(\mathrm{MeD})$ of reductions in IOP and AGMs and the odds ratios (ORs) of the success rates and the incidence of complications were analyzed between $\mathrm{CP}$ and TE in two subgroups, standalone CP versus standalone TE and PCP versus phacotrabeculectomy (PTE). The random effects model was applied in most cases as the heterogeneity was considered present in the enrolled studies for clinical and study differences.

2.5. Sensitivity Analysis, Publication Bias Analysis, and Quality Assessment. Sensitivity analysis was performed for IOP and AGM reductions in CP by deleting the following subgroups: (a) all retrospective studies and (b) studies with small weight (less than the average weight). The publication bias was analyzed with the asymmetry of funnel plot [8]. Neither sensitivity analysis nor funnel plot analysis was conducted in the meta-analysis outcomes between CP and TE, with only 6 literatures enrolled. The quality assessment was performed in the meta-analysis between CP and TE; 1 randomized controlled trial (RCT) was analyzed with the risk of bias table according to the Cochrane Handbook for Systematic Reviews of Interventions [6] and the other 5 non-RCTs were analyzed with the Newcastle-Ottawa Quality 
TABLE 1: Characteristics and baseline information of included literatures.

\begin{tabular}{|c|c|c|c|c|c|c|c|}
\hline & Study type & $\begin{array}{l}\text { Age, mean } \\
\text { (SD) }\end{array}$ & Male\% & $\begin{array}{l}\text { Eyes at } \\
\text { baseline }\end{array}$ & POAG\% & $\begin{array}{c}\text { Baseline IOP, } \\
\text { mean }(\mathrm{SD})\end{array}$ & $\begin{array}{c}\text { Baseline AGMs, } \\
\text { mean (SD) }\end{array}$ \\
\hline \multicolumn{8}{|l|}{ Canaloplasty standalone } \\
\hline Ayyala et al. [10] & Retrospective & $68.3(10.0)$ & 52 & 33 & NA & $21.2(6.6)$ & $2.5(0.8)$ \\
\hline Barnebey [11] & Retrospective & $68.2(13.1)$ & 55 & 20 & 100 & $23.4(4.3)$ & $2.2(1.2)$ \\
\hline Brandao et al. [12] & Prospective & $71.3(7.3)$ & 41 & 19 & 74 & $24.6(5.3)$ & $2.5(0.8)$ \\
\hline Bruggemann and Muller [13] & Retrospective & 62.7 (NA) & 52 & 21 & 100 & $28.8(9.6)$ & $2.9(1.0)$ \\
\hline Brusini [14] & Prospective & $63.5(14.0)$ & NA & 214 & 74 & $29.4(7.9)$ & $3.3(0.9)$ \\
\hline Gandolfi et al. [15] & Retrospective & NA & 67 & 24 & 67 & $26.0(4.0)$ & $2.7(3.3)$ \\
\hline Grieshaber et al. [16] & Prospective & $49.8(15.7)$ & 43 & 60 & 100 & $45.0(12.1)$ & NA \\
\hline Grieshaber et al. [17] & Prospective & $70.8(8.4)$ & 49 & 47 & 100 & $26.8(5.2)$ & $2.8(0.5)$ \\
\hline Grieshaber et al. [18] & Prospective & $71.8(8.8)$ & 41 & 22 & 100 & $27.1(5.3)$ & $2.9(0.6)$ \\
\hline Kalin-Hajdu et al. [19] & Retrospective & $40.0(19.2)$ & NA & 19 & 0 & $30.4(8.4)$ & $3.7(0.8)$ \\
\hline Lewis et al. [20] (CP) & Prospective & $67.6(11.6)$ & 47 & 103 & 89 & $23.5(4.5)$ & $1.9(0.8)$ \\
\hline Lommatzsch et al. [7] & Retrospective & $40.7(21.8)$ & 25 & 14 & 0 & $27.1(12.3)$ & $2.7(1.1)$ \\
\hline Lopes-Cardoso et al. [21] (CP) & Prospective & $73.4(6.0)$ & 66 & 11 & 37 & $24.5(5.1)$ & $3.4(0.5)$ \\
\hline Matlach et al. [22] & RCT & $66.5(11.3)$ & 60 & 30 & 43 & $23.7(5.1)$ & $2.6(1.6)$ \\
\hline Matthaei et al. [23] (CP) & Retrospective & $65.2(12.4)$ & 46 & 33 & 87 & $18.5(6.3)$ & $2.3(1.2)$ \\
\hline Moelle et al. [24] & Retrospective & $62(9)$ & 42 & 26 & 54 & $21.1(5.8)$ & $2.5(1.8)$ \\
\hline Seuthe et al. [25] & Retrospective & $66.7(11.4)$ & NA & 417 & 86 & $20.9(3.5)$ & $3.5(0.9)$ \\
\hline Thederan et al. [26] & Retrospective & $72.9(5.2)$ & 64 & 22 & 68 & $23.7(7.6)$ & $3.1(1.2)$ \\
\hline Voykov et al. [27] & Retrospective & $60(11)$ & 45 & 20 & 75 & $25.7(6.6)$ & $3.4(0.5)$ \\
\hline Wang et al. [28] & Retrospective & $39.1(13.8)$ & 77 & 17 & NA & $24.7(8.7)$ & $2.4(1.7)$ \\
\hline Xin et al. [29] & Prospective & $38(12.8)$ & 65 & 17 & 100 & $29.9(8.2)$ & $2.9(0.9)$ \\
\hline \multicolumn{8}{|l|}{$\begin{array}{l}\text { Canaloplasty with } \\
\text { phacoemulsification }\end{array}$} \\
\hline Arthur et al. [30] & Retrospective & $76.1(8.3)$ & 56 & 32 & 84 & $18.2(5.1)$ & $1.3(0.7)$ \\
\hline Lewis et al. [20] (PCP) & Prospective & $67.6(11.6)$ & 47 & 30 & 89 & $23.5(5.2)$ & $1.5(1.0)$ \\
\hline Lopes-Cardoso et al. [21] (PCP) & Prospective & $73.4(6.0)$ & 66 & 24 & 37 & $19.8(6.8)$ & $3.3(0.5)$ \\
\hline Matlach et al. [31] & Retrospective & $72.9(5.7)$ & 47 & 19 & 47 & $28.3(4.1)$ & $2.8(1.1)$ \\
\hline Matthaei et al. [23] (PCP) & Retrospective & $65.2(12.4)$ & 46 & 13 & 87 & $17.5(4.2)$ & $2.5(1.3)$ \\
\hline Rekas et al. [32] & RCT & $74.6(8.9)$ & 59 & 29 & 83 & $19.0(6.9)$ & $2.6(0.7)$ \\
\hline Schoenberg et al. [33] & Retrospective & $66.8(8.5)$ & 67 & 36 & 94 & $19.5(5.7)$ & NA \\
\hline \multicolumn{8}{|l|}{$\begin{array}{l}\text { Canaloplasty with or without } \\
\text { phacoemulsification, mixed results }\end{array}$} \\
\hline Alobeidan and Almobarak [34] & Retrospective & $53.4(15.0)$ & 60 & 105 & 67 & $19.0(6.7)$ & $2.6(1.3)$ \\
\hline Fujita et al. [35] & Retrospective & $71.7(8.5)$ & NA & 11 & 100 & $23.4(5.5)$ & $2.8(0.6)$ \\
\hline Rekas et al. [36] & Prospective & $69.3(11.4)$ & 40 & 10 & 90 & $19.1(3.4)$ & $2.2(1.1)$ \\
\hline
\end{tabular}

AGM: antiglaucoma medication; CP: independent canaloplasty subgroup in corresponding literature; NA: data not available; PCP: phacocanaloplasty subgroup in corresponding literature; POAG: primary open-angle glaucoma; RCT: randomized controlled trials.

Assessment Scale [9]. All analyses in this part were performed by two researchers (Bing and Jie) independently.

\section{Results}

3.1. Literatures Selection and Characteristics of the Enrolled Studies. 210 records returned from the initial literature search after deduplicating 136 records. 28 records were included in the quantitative analysis, and the other 182 did not meet the eligibility criteria as the process shown in Figure 1. An update of the literature search was made in February 3, 2017, and no new study was enrolled to the quantitative analysis. Table 1 shows the descriptions of the enrolled 28 literatures. 1498 eyes were enrolled at baseline totally, $78 \%$ of which were diagnosed with primary open-angle glaucoma (POAG). The average age of patients at baseline was $62.7 \pm 15.4$ years in the independent $\mathrm{CP}$ subgroup and $71.2 \pm 9.6$ years in the PCP subgroups. The average baseline IOP was $25.1 \pm 8.5 \mathrm{mmHg}$ with $3.04 \pm 1.18$ AGMs in CP standalone subgroup, and the mean baseline IOP was $20.7 \pm 6.4 \mathrm{~mm} \mathrm{Hg}$ with $2.23 \pm 1.14 \mathrm{AGMs}$ in the PCP subgroup.

3.2. The Efficiency of $C P$. The reduction of IOP in all subgroups at 6 months was 10.69 (95\% CI 8.96 to12.43) 
TABle 2: Meta-analysis outcomes of reductions in IOP and antiglaucoma medications (AGMs) at 6 and 12 months postoperationally.

\begin{tabular}{lccr}
\hline & & IOP reduction (95\% CI) mmHg & AGMs, reduction (95\% CI) \\
\hline \multirow{2}{*}{ Standalone canaloplasty } & 6 months & $12.01(9.77,14.24)$ & $2.01(1.51,2.50)$ \\
& 12 months & $11.38(9.43,13.34)$ & $2.16(1.79,2.53)$ \\
Phacocanaloplasty & 6 months & $8.32(5.36,11.27)$ & $2.03(1.36,2.70)$ \\
& 12 months & $8.14(4.83,11.46)$ & $2.04(1.15,2.92)$ \\
\hline
\end{tabular}

TABLE 3: Incidence of complications of canaloplasty.

\begin{tabular}{lc}
\hline Complications & Incidence\% (events/pooled eyes) \\
\hline Hyphema (blood layer $>1 \mathrm{~mm})$ & $24.9(304 / 1221)$ \\
Hypotony $<5 \mathrm{mmHg}$ & $8.6(94 / 1091)$ \\
Descemet membrane detachment & $3.1(37 / 1185)$ \\
Detectable conjunctival bleb & $1.9(17 / 899)$ \\
\hline
\end{tabular}

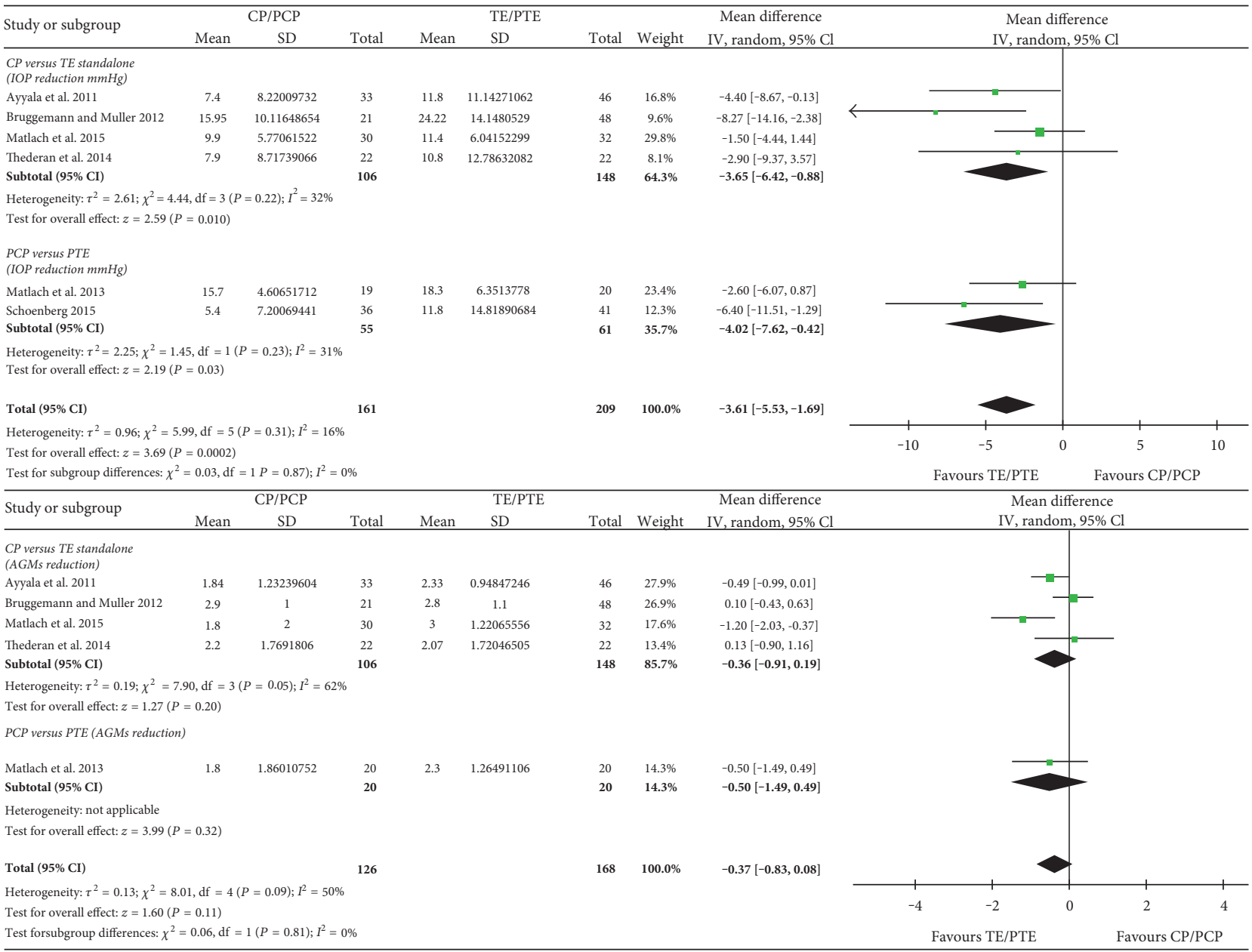

FIGURE 2: Comparison of the reductions in IOP and antiglaucoma medications (AGMs) between canaloplasty (CP) and trabeculectomy (TE) $(\mathrm{PCP}=$ phacocanaloplasty, $\mathrm{PTE}=$ phacotrabeculectomy $)$. 


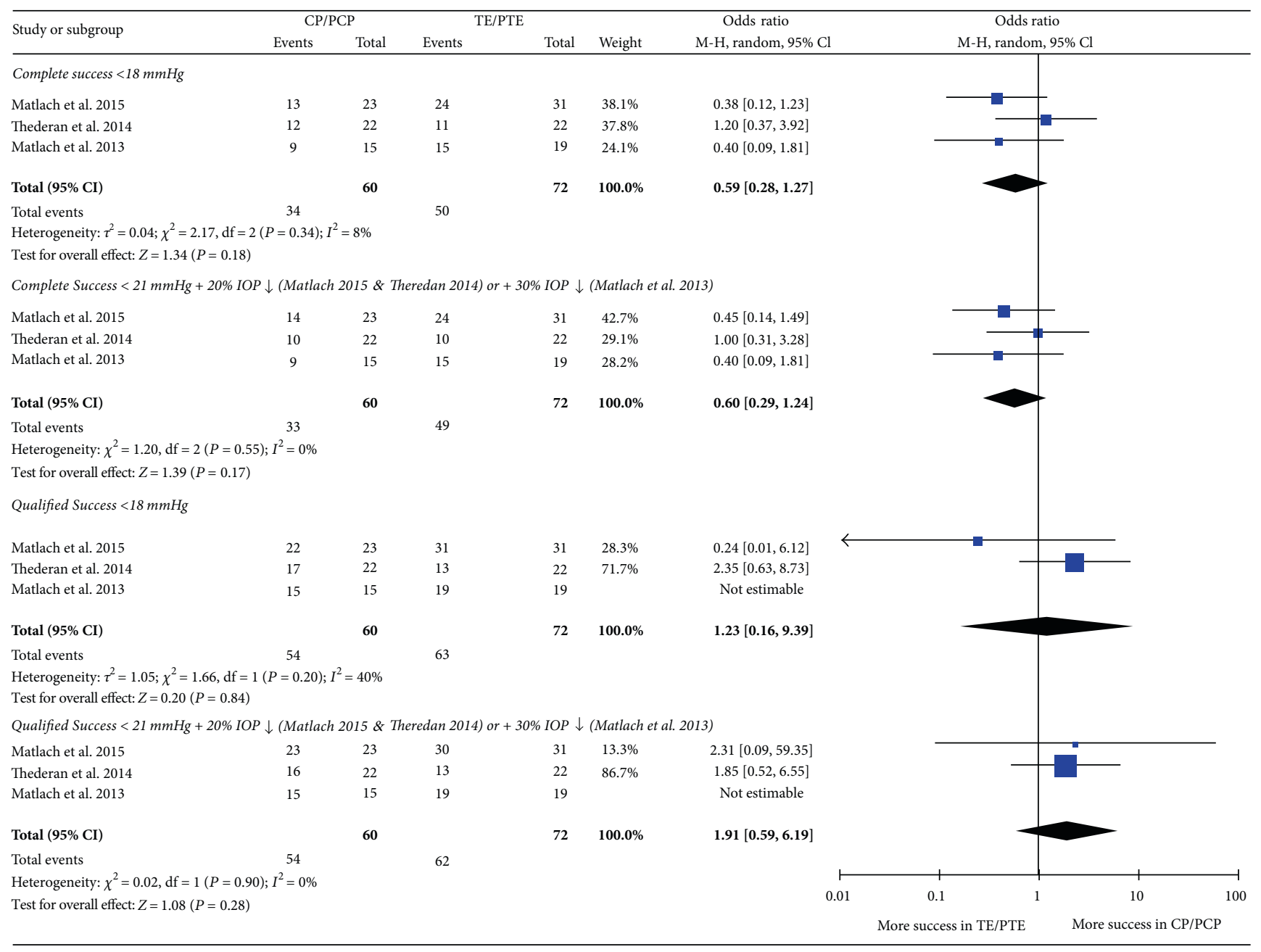

FIGURE 3: Comparison of success rates between canaloplasty (CP) and trabeculectomy (TE) (independent CP versus TE in Matlach et al. [22] and Thederan et al. [26]; PCP versus PTE in Matlach [31]; PCP = phacocanaloplasty, PTE = phacotrabeculectomy).

mmHg with 2.03 (95\% CI 1.69 to 2.37) less AGM use and at 12 months was 9.94 (95\% CI 8.42 to 11.45$) \mathrm{mmHg}$ with 2.11 (95\% CI 1.80 to 2.42) less AGM use. Table 2 shows more information of the meta-analysis results (detailed information and the forest plots in Online Resource Figures 1-4 in Supplementary Material available online at https:/doi.org/ $10.1155 / 2017 / 2723761)$.

3.3. The Complications of CP. Table 3 summarizes the incidence of complications of CP (included PCP). The most common one was hyphema; hyphema (blood layer $>1 \mathrm{~mm}$ ) could be observed in about every four enrolled eyes (24.9\%). The incidence of the other complications in CP is shown in Table 3.

\subsection{Comparison of $C P$ and TE}

3.4.1. Reductions in IOP and AGMs. The meta-analysis results of the MeDs between TE and CP of the reductions in IOP and AGMs at 12 months after surgery are shown in Figure 2 (data at 6 months used in Bruggemann and Muller [13]). TE was more efficient in IOP control than CP, with a MeD of 3.61 (95\% CI, 1.695.53) $\mathrm{mmHg}$. However, no significant difference was found in the reduction of AGMs between $\mathrm{CP}$ and TE, with a $\mathrm{MeD}$ of -0.37 (95\% CI $-0.830 .08)$.

3.4.2. The Success Rates. The complete and qualified success rates were compared between $\mathrm{CP}$ and TE at 12 months in three studies $[22,26,31]$ as shown in Figure 3. No significant difference in the success rates was found between CP and TE in all comparisons shown in Figure 3.

3.4.3. The Complications. The complications were compared between CP and TE in five researches [10, 22, 26, 31, 33] with ORs as shown in Figure 4. The hyphema was more prevalent in CP with an OR of 9.24 (95\% CI, 3.09 to 27.60). The Descemet membrane detachment was only observed in CP with a reported incidence of $3 \%$. The suprachoroidal hemorrhage and bleb needling were only reported in TE with incidences of $2.3 \%$ and $10.9 \%$, respectively. TE was with significantly higher incidences in hypotony and the choroidal effusion/detachment. No significant difference was found in the incidence of conjunctiva leakage (OR 0.72, 95\% CI 0.16 to 3.14 ). 


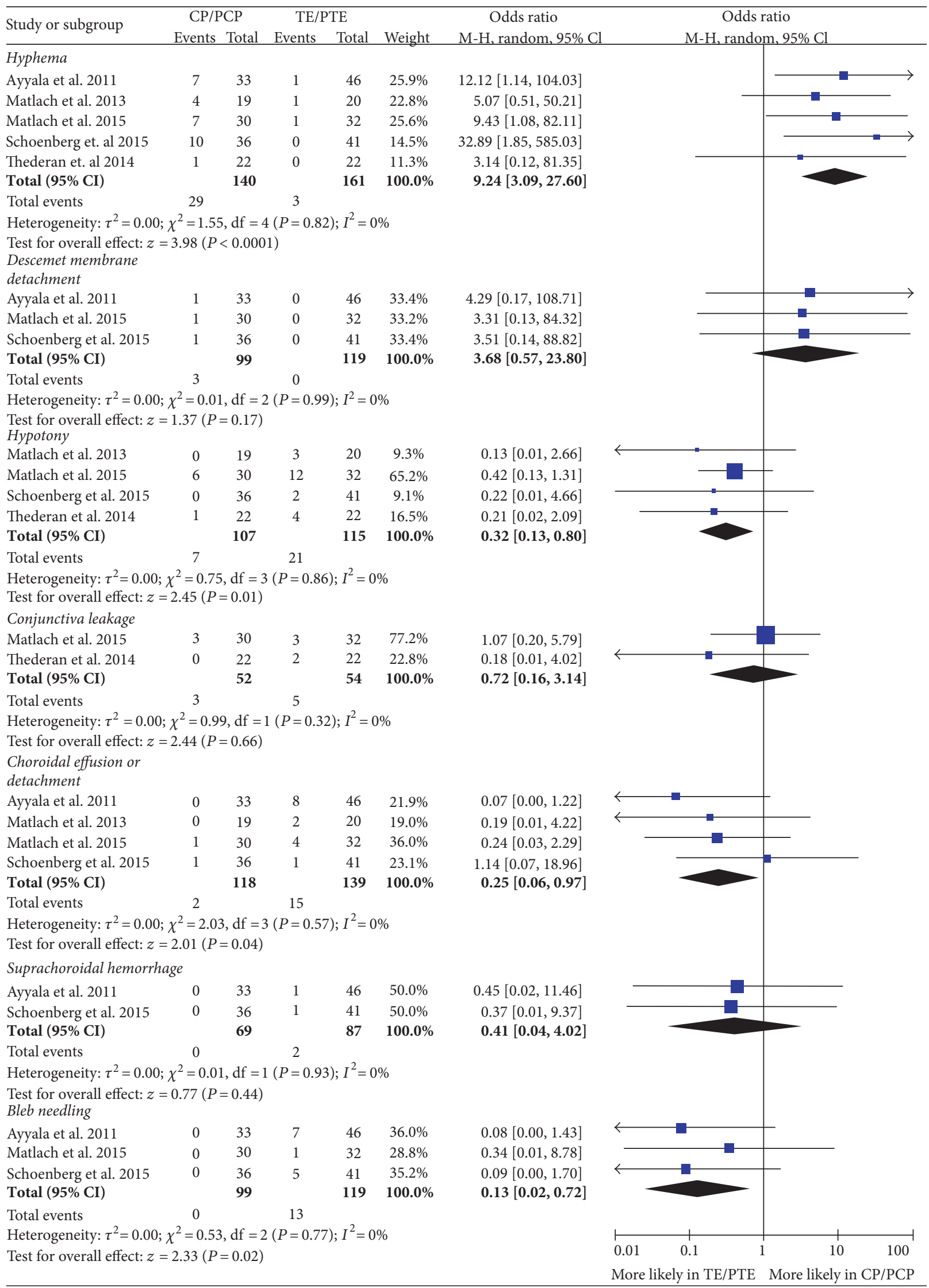

FIgURE 4: Comparison of complications between canaloplasty (CP) and trabeculectomy (TE). 
3.4.4. Sensitivity Analysis. In sensitivity analysis, the difference between before and after removing all retrospective studies in the IOP reductions was $14 \%$ at 6 months and $17 \%$ at 12 months; the corresponding difference in the AGM reductions was 5\% at 6 months and 5\% at 12 months. The difference between before and after removing the small weight studies in the IOP reduction was $-3 \%$ at 6 months and $-9 \%$ at 12 months; the corresponding change in the AGM reduction was $4 \%$ at 6 months and $0 \%$ at 12 months (detailed data in the Online Resource Table 1). The publication bias analysis and the quality assessment were given in the discussion part.

\section{Discussion}

As far as we know, this was the first system review of $\mathrm{CP}$ in glaucoma control. At one year after $\mathrm{CP}$, IOP decreased by 9.94 (95\% CI 8.42 to 11.45 ) mmHg with 2.11 (95\% CI 1.80 to 2.42) less AGM use. TE was shown to be more efficient in IOP control than in CP, with 3.61 (95\% CI, 1.69 to 5.53) $\mathrm{mmHg}$ more IOP reduction at 12 months postoperationally. Our finding confirmed the conclusion of Rulli's metaanalysis that NPS was less effective than TE in decreasing IOP and also supported the opinion that canal surgery was less effective than TE in IOP control [3]. However, no significant difference between $\mathrm{CP}$ and TE was found in the AGM reduction and in the complete or qualified success rates at 1 year after surgery. $\mathrm{CP}$ was able to achieve similar postoperative success rates and reduce the number of the AGMs likewise.

In $\mathrm{CP}$, hyphema was the most prevalent complication and nearly one in every four eyes would experience $\geq 1 \mathrm{~mm}$ hyphema. However, studies showed postoperative hyphema might indicate a better IOP control after $\mathrm{CP}$, as it might be associated with restored aqueous outflow system [17, 37]. Descemet membrane detachment (DMD) was not a common complication after CP with an incidence of 3\% in this review, and most DMD could be resolved without longlasting sequelae and its risk might be decreased by avoiding excessive injection into the Schlemm canal during viscodilation [38]. However, one 86-year-old man was reported to develop keratoplasty-needing corneal decompensation from DMD after CP [38].

Comparing complications between $\mathrm{CP}$ and TE, hyphema was more common in $\mathrm{CP}$, but might be a good indicator for $\mathrm{CP}$ as mentioned before. DMD was only reported in $\mathrm{CP}$ and could be related to the Schlemm canal injection [38]. Hypotony and choroidal effusion/detachment were more common in TE than in $\mathrm{CP}$, which was in agreement with former research [3]. In TE, hypotony might be the result of high filtration, while choroidal effusion often occurred with hypotony. Suprachoroidal hemorrhage, a severe complication, was only reported in TE with an incidence of $2.3 \%$ in this review $[10,33]$. Bleb needling was an intervention reported in $10.9 \%$ of eyes after TE and in no eyes after CP as an NPS. To sum up, TE was associated with more complications than CP.

$\mathrm{CP}$ was reported with higher patient satisfaction than TE in a multiquestionnaire study conducted two years after surgery [39]. Another cost-effectiveness study indicated that although the surgery fee was higher in $\mathrm{CP}$, the longer hospitalization, higher readmission rates, and more frequent postoperative interventions of TE displayed opportunity costs [13], which should be taken into consideration.

In the sensitivity analysis, the outcomes of the metaanalysis of the reductions in IOP and AGMs after CP were robust, especially after removing small weight studies. The publication bias might exist with missing studies on the left hand side of the funnel plots of IOP reduction at 6 months (Online Resource Figure 5) and 12 months (Online Resource Figure 6) after surgery [8]. In the quality assessment of the enrolled 6 studies comparing $\mathrm{CP}$ with TE, the RCT [22] showed higher risk of performance, detection, and attrition bias (Online Resource Figure 7). For the other 5 retrospective studies, the main problem existed in the selection of the controls (Online Resource Table 2), as clinical heterogeneity might exist between the $\mathrm{CP}$ cases and the TE controls.

One main limitation of this system review was the quality of the enrolled studies. Without limitation of research types as few RCTs were available, 18 of the 28 eligible literatures were retrospective studies, a study type with relatively low evidence level. Moreover, not many studies about the comparison between $\mathrm{CP}$ and TE were available, and only 1 was an RCT and the other 5 were retrospective. Another limitation was no unpublished data were enrolled in this review while the funnel plot indicated publication bias might exist.

\section{Conclusion}

$\mathrm{CP}$ was less effective in IOP reduction than $\mathrm{TE}$, but $\mathrm{CP}$ was able to achieve similar postoperative success rates and reduce the number of the AGMs likewise. $\mathrm{CP}$ was also associated with lower incidence of complications and was reported with higher patient satisfaction. More high-quality studies, especially properly designed RCTs, are needed to verify our findings in this system review.

\section{Conflicts of Interest}

The authors declare that they have no conflicts of interest.

\section{Acknowledgments}

This study is funded by the National Major Scientific Equipment program (Grant no. 2012YQ12008005).

\section{References}

[1] Collaborative Normal-Tension Glaucoma Study Group, "Comparison of glaucomatous progression between untreated patients with normal-tension glaucoma and patients with therapeutically reduced intraocular pressures," American Journal of Ophthalmology, vol. 126, no. 4, pp. 487-497, 1998.

[2] D. F. Garway-Heath, D. P. Crabb, C. Bunce et al., "Latanoprost for open-angle glaucoma (UKGTS): a randomised, multicentre, placebo-controlled trial," Lancet, vol. 385, no. 9975, pp. 1295-1304, 2015.

[3] E. Rulli, E. Biagioli, I. Riva et al., "Efficacy and safety of trabeculectomy vs nonpenetrating surgical procedures: a 
systematic review and meta-analysis," JAMA Ophthalmology, vol. 131, no. 12, pp. 1573-1582, 2013.

[4] N. S. Borisuth, B. Phillips, and T. Krupin, "The risk profile of glaucoma filtration surgery," Current Opinion in Ophthalmology, vol. 10, no. 2, pp. 112-116, 1999.

[5] N. Koerber, "Canaloplasty - a new approach to nonpenetrating glaucoma surgery," Techniques in Ophthalmology, vol. 5, no. 3, pp. 102-106, 2007.

[6] J. P. T. Higgins and S. Green, Cochrane handbook for systematic reviews of interventions version 5.1.0, 2011, February 2016, http://handbook.cochrane.org/.

[7] C. Lommatzsch, C. Heinz, A. Heiligenhaus, and J. M. Koch, "Canaloplasty in patients with uveitic glaucoma: a pilot study," Graefe's Archive for Clinical and Experimental Ophthalmology, vol. 254, no. 7, pp. 1325-1330, 2016.

[8] J. A. C. Sterne, A. J. Sutton, J. P. A. Ioannidis et al., "Recommendations for examining and interpreting funnel plot asymmetry in meta-analyses of randomised controlled trials," British Medical Journal, vol. 343, p. d4002, 2011.

[9] G. A. Wells, D. O'Connell, J. Peterson, V. Welch, M. Losos, and P. Tugwell, The Newcastle-Ottawa Scale (NOS) for assessing the quality of nonrandomised studies in meta-analyses, 2014, March 2016, http://www.ohri.ca/programs/clinical_ epidemiology/oxford.asp.

[10] R. S. Ayyala, A. L. Chaudhry, C. B. Okogbaa, and D. Zurakowski, "Comparison of surgical outcomes between canaloplasty and trabeculectomy at 12 months' follow-up," Ophthalmology, vol. 118, no. 12, pp. 2427-2433, 2011.

[11] H. S. Barnebey, "Canaloplasty with intraoperative low dosage mitomycin C: a retrospective case series," Journal of Glaucoma, vol. 22, no. 3, pp. 201-204, 2013.

[12] L. M. Brandao, A. Schotzau, and M. C. Grieshaber, "Suture distension of Schlemm's canal in canaloplasty: an anterior segment imaging study," Journal of Ophthalmology, vol. 2015, p. $457605,2015$.

[13] A. Bruggemann and M. Muller, "Trabeculectomy versus canaloplasty - utility and cost-effectiveness analysis. [German]," Klinische Monatsblätter für Augenheilkunde, vol. 229, no. 11, pp. 1118-1123, 2012.

[14] P. Brusini, "Canaloplasty in open-angle glaucoma surgery: a four-year follow-up," Scientific World Journal, vol. 2014, Article ID 469609, p. 7, 2014.

[15] S. A. Gandolfi, N. Ungaro, S. Ghirardini, M. G. Tardini, and P. Mora, "Comparison of surgical outcomes between canaloplasty and Schlemm's canal scaffold at 24 Months' follow-up," Journal of Ophthalmology, vol. 2016, p. 3410469, 2016.

[16] M. C. Grieshaber, A. Pienaar, J. Olivier, and R. Stegmann, "Canaloplasty for primary open-angle glaucoma: long-term outcome," The British Journal of Ophthalmology, vol. 94, no. 11, pp. 1478-1482, 2010.

[17] M. C. Grieshaber, A. Schoetzau, J. Flammer, and S. Orgul, "Postoperative microhyphema as a positive prognostic indicator in canaloplasty," Acta Ophthalmologica, vol. 91, no. 2, pp. 151-156, 2013.

[18] M. C. Grieshaber, H. R. Grieshaber, and R. Stegmann, “A new expander for Schlemm Canal surgery in primary open-angle glaucoma-interim clinical results," Journal of Glaucoma, vol. 25, no. 8, pp. 657-662, 2016.

[19] E. Kalin-Hajdu, K. Hammamji, S. Gagne, and P. Harasymowycz, "Outcome of viscodilation and tensioning of Schlemm's canal for uveitic glaucoma," Canadian Journal of Ophthalmology, vol. 49, no. 5, pp. 414-419, 2014.

[20] R. A. Lewis, K. von Wolff, M. Tetz et al., "Canaloplasty: three-year results of circumferential viscodilation and tensioning of Schlemm canal using a microcatheter to treat open-angle glaucoma," Journal of Cataract and Refractive Surgery, vol. 37, no. 4, pp. 682-690, 2011.

[21] I. Lopes-Cardoso, F. Esteves, M. Amorim, G. Calvao-Santos, M. L. Freitas, and J. Salgado-Borges, "Circumferential viscocanalostomy with suture tensioning in Schlemm canal (canaloplasty)-one year experience. [Spanish]," Archivos de la Sociedad Española de Oftalmología, vol. 88, no. 6, pp. 207-215, 2013.

[22] J. Matlach, C. Dhillon, J. Hain, G. Schlunck, F. Grehn, and T. Klink, "Trabeculectomy versus canaloplasty (TVC study) in the treatment of patients with open-angle glaucoma: a prospective randomized clinical trial," Acta Ophthalmologica, vol. 93, no. 8, pp. 753-761, 2015.

[23] M. Matthaei, J. Steinberg, A. Wiermann, G. Richard, and M. Klemm, "Canaloplasty: a new alternative in nonpenetrating glaucoma surgery. [German, English]," Der Ophthalmologe, vol. 108, no. 7, pp. 637-643, 2011.

[24] M. C. Moelle, C. Cursiefen, R. Rejdak, F. K. Horn, and A. G. Junemann, "Time course of induced astigmatism after canaloplasty," Journal of Glaucoma, vol. 23, no. 1, pp. e53-e59, 2014.

[25] A. M. Seuthe, C. Ivanescu, S. Leers, K. Boden, K. Januschowski, and P. Szurman, "Modified canaloplasty with suprachoroidal drainage versus conventional canaloplasty-1-year results," Graefe's Archive for Clinical and Experimental Ophthalmology, vol. 254, no. 8, pp. 1591-1597, 2016.

[26] L. Thederan, F. Grehn, and T. Klink, "Comparison of canaloplasty with trabeculectomy. [German]," Klinische Monatsblätter für Augenheilkunde, vol. 231, no. 3, pp. 256-261, 2014.

[27] B. Voykov, G. Blumenstock, M. A. Leitritz, S. Dimopoulos, and O. Alnahrawy, "Treatment efficacy and safety of canaloplasty for open-angle glaucoma after 5 years," Clinical \& Experimental Ophthalmology, vol. 43, no. 8, pp. 768-771, 2015.

[28] N. Wang, H. Wang, J. Hong et al., "The comparison of shortterm outcome between aqueous drainage pathway reconstruction surgery versus canaloplasty for open angle glaucoma. [Chinese]," Chinese Journal of Ophthalmology, vol. 50, no. 5, pp. 338-342, 2014.

[29] C. Xin, X. Chen, Y. Shi, H. Wang, and N. Wang, "Modified canaloplasty: a new, effective, and safe option for glaucoma patients with a disrupted Schlemm Canal wall," Journal of Glaucoma, vol. 25, no. 10, pp. 798-801, 2016.

[30] S. N. Arthur, L. B. Cantor, D. WuDunn et al., "Efficacy, safety, and survival rates of IOP-lowering effect of phacoemulsification alone or combined with canaloplasty in glaucoma patients," Journal of Glaucoma, vol. 23, no. 5, pp. 316-320, 2014.

[31] J. Matlach, F. J. Freiberg, S. Leippi, F. Grehn, and T. Klink, "Comparison of phacotrabeculectomy versus phacocanaloplasty in the treatment of patients with concomitant cataract and glaucoma," BMC Ophthalmology, vol. 13, p. 1, 2013.

[32] M. Rekas, A. Byszewska, K. Petz, J. Wierzbowska, and A. Junemann, "Canaloplasty versus non-penetrating deep sclerectomy - a prospective, randomised study of the safety and efficacy of combined cataract and glaucoma surgery; 12-month follow-up," Graefe's Archive for Clinical and Experimental Ophthalmology, vol. 253, no. 4, pp. 591-599, 2015. 
[33] E. D. Schoenberg, A. L. Chaudhry, R. Chod, D. Zurakowski, and R. S. Ayyala, "Comparison of surgical outcomes between phacocanaloplasty and phacotrabeculectomy at 12 Months' follow-up: a longitudinal cohort study," Journal of Glaucoma, vol. 24, no. 7, pp. 543-549, 2015.

[34] S. A. Alobeidan and F. A. Almobarak, "Incidence and management of haemorrhagic Descemet membrane detachment in canaloplasty and phacocanaloplasty," Acta Ophthalmologica, vol. 94 , no. $5,2015$.

[35] K. Fujita, K. Kitagawa, Y. Ueta, T. Nakamura, A. Miyakoshi, and A. Hayashi, "Short-term results of canaloplasty surgery for primary open-angle glaucoma in Japanese patients," Case Reports in Ophthalmology, vol. 2, no. 1, pp. 65-68, 2011.

[36] M. Rekas, M. E. Danielewska, A. Byszewska et al., "Assessing efficacy of canaloplasty using continuous 24-hour monitoring of ocular dimensional changes," Investigative Ophthalmology \& Visual Science, vol. 57, no. 6, pp. 2533-2542, 2016.

[37] J. M. Koch, A. Heiligenhaus, and C. Heinz, "Canaloplasty and transient anterior chamber haemorrhage: a prognostic factor? [German]," Klinische Monatsblätter für Augenheilkunde, vol. 228, no. 5, pp. 465-467, 2011.

[38] A. Jaramillo, J. Foreman, and R. S. Ayyala, "Descemet membrane detachment after canaloplasty: incidence and management," Journal of Glaucoma, vol. 23, no. 6, pp. 351354, 2014.

[39] T. Klink, J. Sauer, N. J. Korber et al., "Quality of life following glaucoma surgery: canaloplasty versus trabeculectomy," Clinical Ophthalmology, vol. 9, pp. 7-16, 2015. 


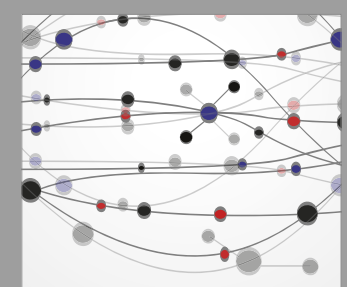

The Scientific World Journal
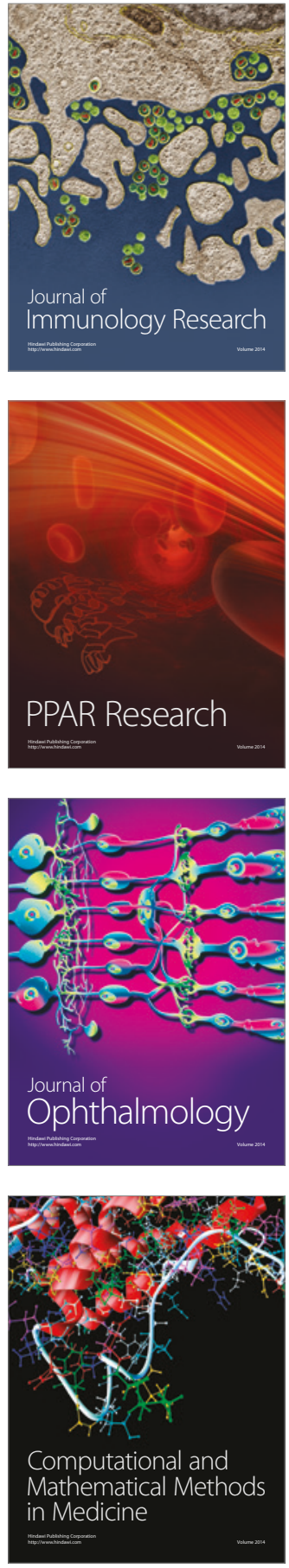

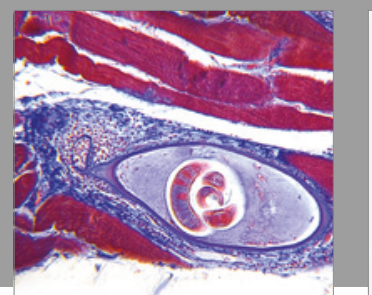

Gastroenterology Research and Practice
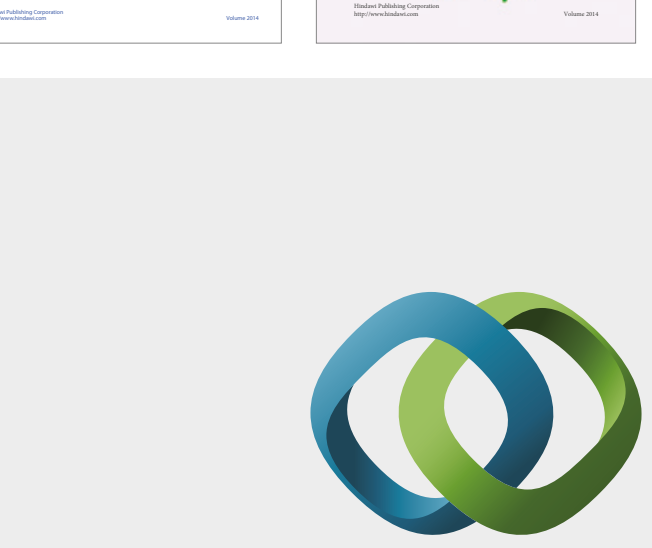

\section{Hindawi}

Submit your manuscripts at

https://www.hindawi.com
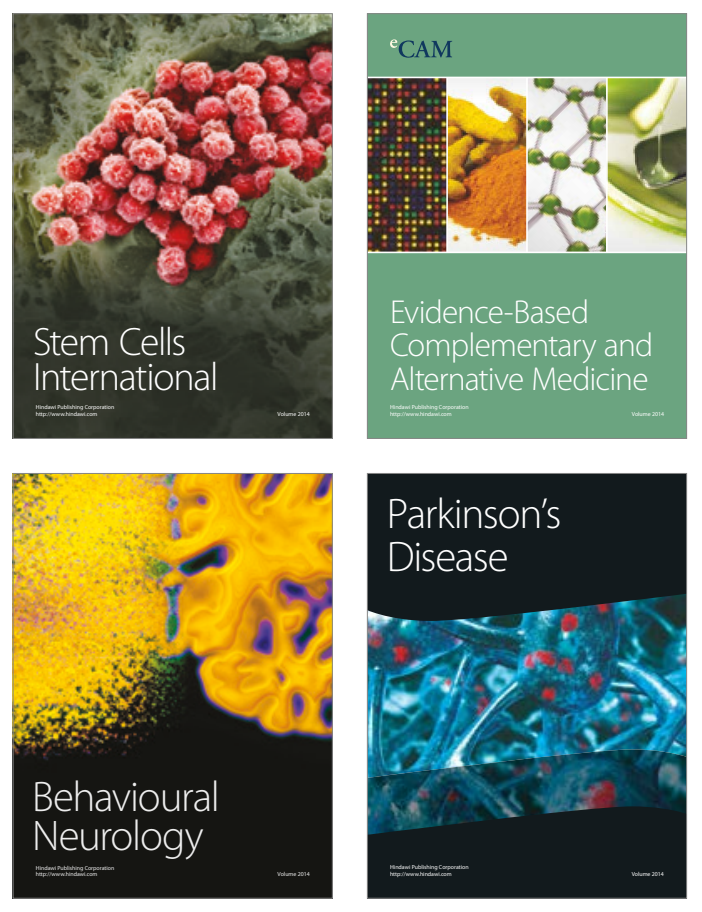
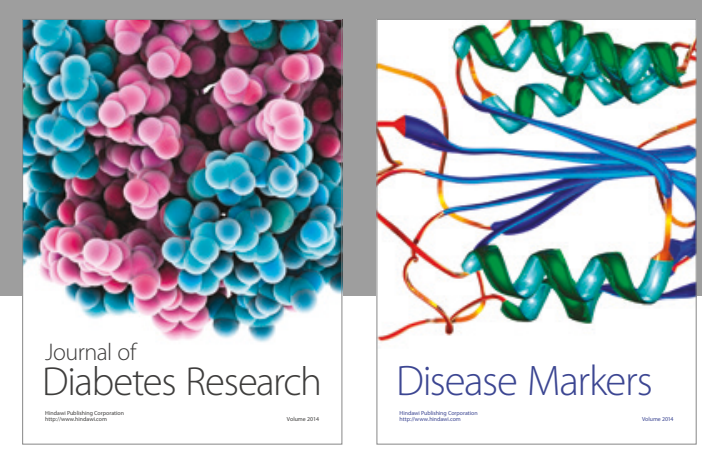

Disease Markers
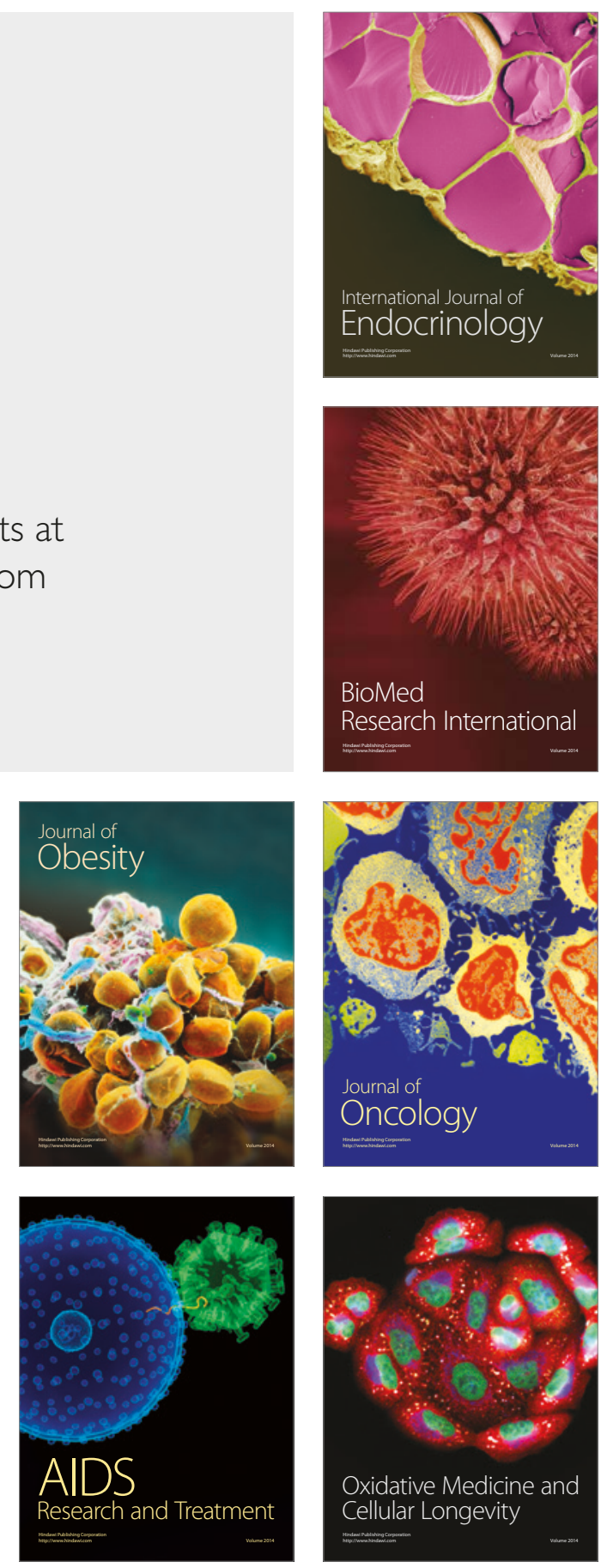